\title{
The ethics of medical involvement in torture
}

\author{
R S Downie Glasgow University, Scotland
}

\section{Author's abstract}

The difficulties of establishing a definition of torture are discussed, and a definition is suggested. It is then argued that, irrespective of general ethical questions, doctors in particular should never be involved because of their social role.

If we think of a definition as being a set of necessary and sufficient conditions which uniquely identify what is in question then a definition of torture, as distinct from cruelty or degrading treatment or sustained violence against a person, is not easy to establish. From a practical point of view it does not really matter very much whether a practice is strictly torture or some other form of inhuman treatment; the point would be to get it stopped. But since I have been asked to give a philosophical account of torture then my first task is to try to identify precisely what we ought to mean when we use the term.

As a first attempt we might try the following: Torture is the deliberate infliction of pain on another person or persons. Dut this will not do. First of all, many medical treatments involve the infliction of pain so we need to add the phrase 'without the consent of the person'. Secondly, it is possible, perhaps all too common, for someone to torture an animal, and it is a moot point whether one animal (for example a cat) can torture another. We can meet these points by simple amendments: Torture is the deliberate infliction of pain on another sentient being without consent. But ordinary assault would fit that definition, so we must add that the victim must be held in captivity. Yet suppose that someone in captivity is systematically beaten up. Is that torture? We might say that it is inhuman and degrading treatment, but not quite torture. True, torture can be used in order to degrade, but not all degrading treatment is torture.

A possible way ahead here might be to suggest that torture always has some objective beyond itself. In other words, whereas degrading treatment need

\section{Key words}

Torture; medical skills; medical role. have no objective beyond degrading, torture must have some objective beyond torturing - such as the extraction of information, the gratification of the torturer, or as a punishment. We could perhaps unify these objectives by saying that torture always involves the infliction of pain with the aim of subjugating a sentient being to the ends of others. Yet sometimes the Inquisition tortured heretics for their own good, in order to force them to see the error of their beliefs. Of course, it is true that such an objective might be difficult to distinguish from torture as a punishment for heresy or torture as a gratification for the torturers, but certainly some torture waso intended to bring heretics to their senses for their own good. Nevertheless, we can accommodate torture for the victim's own good in the means/end analysis if we say that the pain of the body was used as a means to the end of the soul's repentance. We can now incorporate these points in a revised definition: Torture is the deliberate infliction of pain on another captive sentient being in order to use the being as a means to an end to which he/she has not consented.

There is room for further refinements. First, not all torture involves what is fairly called pain. For example, sensory deprivation might be used in torture and perhaps there can be mental torture which is not exactly pain. But this difficulty is easy to take care of by adding to the definition: 'pain, or other severe distress'. Secondly, can we be said to be able to torture ourselves? This idea is on the margins of the metaphorical. The captivity is that of our own psychological experience, the 'mind-forg'd manacles', as the poet Blake puts it; and the pain or the unpleasantness is that of repeatedly going over in our minds some episodes in which we behaved badly, with the objective of self-punishment. It is clearly no job for Amnesty to deal with self-torture, but there is no doubt that it is sometimes the job of psychiatrists. The final point to note about the definition - it is not a refinement but an attempt to avoid confusion - is that the victims of torture need not be 'innocent'. Those who are entirely justly convicted criminals or terrorists can still be said to be tortured. Indeed, they frequently are. We are left then with the following definition: 
Torture is the deliberate infliction of pain or other severe distress by one sentient being on another who is in captivity and involves using that being as a means to an end to which the being has not consented.

\section{Moral aspects}

The main question I wish to address in this second part of my discussion is whether doctors should ever be involved with torture. Of course, if it could be established that no one should ever be involved in torture then it would follow that doctors should not - the greater set would contain the lesser. But it is not easy to establish that no one should ever be involved in torture, and I shall not try to do so in this short paper. Yet even if we cannot establish that no one should ever in any circumstances be involved in torture it may still be possible to establish that doctors should never be involved; there may be features of being a doctor that make it always wrong for the doctor qua doctor to be involved, even although in rare instances others may legitimately be involved. For example, there may sometimes be cases in which it would be possible by torture to extract information from evil terrorists which would save the lives of thousands of innocent civilians. The fact that examples of this sort are more common in philosophy books than in reality does not really affect the point that it is at least logically possible that in certain circumstances the use of torture to extract life-saving information may be morally legitimate. As I said, I am not arguing for this case but simply noting it as an assumption which lets me proceed to the question of whether, even if it is the case, we can argue that doctors in particular should never be involved.

Before we proceed to this question we must try to dispose of an unattractive possibility which is created by the assumption that in some cases torture may be legitimate. The unattractive possibility is that if we once allow that torture could sometimes be morally legitimate it might be claimed to be morally obligatory in some cases for doctors themselves to be the torturers. The argument here is that doctors more than most have the skills necessary to torture with the minimum damage to the victim. Of course, this consideration could not justify a doctor in torturing for just any sort of objective, but only for one which was conducive to the good of others. This idea that the skills of the doctor can be used for an end other than healing is an old one. Plato in the Republic (333e) notes that the good doctor can also be the good poisoner. Here Plato is thinking of the art of medicine as what he calls a 'techne', a kind of skill which can be used for an end which may be good or bad. Can we reply to this argument?

A reply involves some consideration of the sort of job being a doctor is. Some jobs are basically what we might call 'skill jobs'. For example, the essence of the job of musician is a skill or skills; if you do not have the skills you are no musician. Other jobs are fundamentally 'aim jobs'. For example, the job of 'farmer' is one such. A farmer by definition is one who cultivates fields or animals. Even if he is very unskilful he remains a farmer to the extent that that is what he is aiming to do. Thirdly, some jobs are 'role jobs'. For instance, the job of postman is a 'role job'. If I deliver a letter as a private person, I am only metaphorically a postman, for I am not authorised with official rights and duties. On the other hand, if I am the authorised postman, then, even if I have no skills, for example if I get lost with my mail-bag, and even if I have criminal aims, for example to steal the mail, I am still the postman because I have been authorised in that role. Obviously, these distinctions need much refinement, and many jobs will combine more than one of the characteristics. But medicine has all three. If a person has no skills he is no doctor. More controversially, the doctor must be defined as having a certain aim, which I suggest is that of relieving suffering or, more ambitiously, that of healing. A doctor also has a role, defined in terms of a set of rights and duties authorised by some sort of governing body, and often strengthened by an official code of ethics. If a doctor fails under any of these aspects of his job he is not acting as a doctor. Let us now apply this analysis of the concept of a doctor to the question of whether the doctor may or must be involved in torture.

The first step requires me to clarify what is meant by the vague phrase I have been using up till now: 'involved in torture'. It can mean at least three things. A doctor may be 'involved in torture' if:

(a) he attempts to heal the victims of torture;

(b) he himself engages in torture either by advising or by actually carrying it out;

(c) he examines possible victims knowing or suspecting that torture will follow.

There seems no problem about (a). It is part of the aim and role of the doctor to heal, and this is the proper purpose of his skills. Turning to (b) I can argue that it follows from my account of what it is to be a doctor that it must always be wrong for the doctor qua doctor to engage in torture either by offering advice or by carrying it out. Of course, sometimes a doctor may have the skills to pretend that he is engaged in torture but not actually do so. But that situation, a highly unlikely one, is not really a case of the doctor engaging in torture, but only of pretending to do so.

What of case (c)? Should a doctor examine someone with the objective of deciding whether the victim can stand up to torture? It might depend on what was involved. If such an examination would enable the doctor to say that he believes the victim is likely to die of heart-failure if tortured then perhaps this kind of activity is within the role of the doctor and compatible with his intrinsic aim. Perhaps he might 
even say falsely that the victim would die in order to protect him. But cases of these types must be rare.

What has emerged is that 'doctor' is an evaluative term. I am asserting that it is part of the concept of a doctor that a doctor must aim at relieving suffering or healing and that he also has a certain role in society. I am rejecting the view that the job of doctor can be adequately defined only in terms of the possession of certain skills. The skills of a musician, for example, can be used for a good or bad end, but not those of a doctor. Again, the skills and knowledge of a scientist can be used for good or bad ends. But if a doctor uses his skills for a bad end then he is no doctor. Note that the point is not just that the doctor's skills must be used for a good end. For if torture is sometimes justifiable, for example to prevent a terrorist plot, then torture will be being used for a good end. The point is that the skills of a doctor must be used only for a certain sort of good end - healing or relieving suffering. If a person uses them for any other purpose then he has given up being a doctor.

Since this is the central point in my argument it may be worthwhile to expand on it briefly. As I said, the essence of being a musician is the possession of skills. If the musician exercises his skills to soothe a tyrant he is still a musician. Similarly, a scientist has skills and knowledge and remains a scientist even if he puts these to a morally bad end, such as devising chemical weapons. He is a bad scientist if, but only if, he falsifies his results. The doctor can be criticised from three standpoints; if his skills are defective, if the role is not fulfilled adequately (for example when the doctor does not take his/her turn on the rota), and, most relevant here, when the aim is not to relieve suffering or encourage healing.

My argument clearly entails that the profession of medicine has certain values built into it. It is worth noting two implications of this position. First, it prevents a doctor defending himself by saying:
'When in Rome do as the Romans'. For example, the practice of female circumcision is mutilating and a doctor qua doctor should never be involved in it, regardless of any local customs. Similarly, it will not do for a doctor to say that torture is endemic in his community so he must go along with it. Medicine stands for something. I am asserting that what it stands for is the ideal of using scientific and other skills by an authorised or legitimated person who has the aim of alleviating suffering or healing. Secondly, it implies 'once a doctor always a doctor'. In other words, it is not open for a doctor to say 'I shall cease acting as a doctor while I engage in torture and then I shall resume the role later'. Being a doctor is more like being a parent than being a postman; resignation is not possible.

The whole argument might have been by-passed by quoting the first clause of the Declaration of Tokyo (adopted by the World Medical Association in 1975) which states unequivocably:

'The doctor shall not countenance, condone or participate in the practice of torture or other forms of cruel, inhuman or degrading procedures, whatever the offence of which the victim of such procedures is suspected, accused or guilty, and whatever the victim's beliefs, or motives, and in all situations including armed conflict and civil strife.'

But however convincing codes are as pieces of deontology it is always philosophically interesting to consider what sort of justification can be given of what is intuitively judged to be binding on doctors.

\section{$R S$ Downie is Professor of Moral Philosophy at Glasgow University.}

This symposium derives from a joint symposium of the Institute of Medical Ethics and The Royal College of Physicians held in 1991. 